Article

\title{
Comparison of Oxalate, Citrate and Tartrate Ions Adsorption in the Hydroxyapatite/Aqueous Electrolyte Solution System
}

\author{
Władysław Janusz and Ewa Skwarek * \\ Faculty of Chemistry, Maria Curie Skłodowska University, M.C. Skłodowskiej Square 3, 20-031 Lublin, Poland; \\ wladyslaw.janusz@poczta.umcs.lublin.pl \\ * Correspondence: ewunias@hektor.umcs.lublin.pl; Tel.: +48-604-871-100
}

Received: 4 September 2020; Accepted: 12 October 2020; Published: 15 October 2020

check for updates

\begin{abstract}
The kinetics of adsorption/desorption of oxalate, citrate and tartrate anions was investigated using hydroxyapatite from solutions at the initial concentrations of 0.000001 and $0.001 \mathrm{~mol} / \mathrm{dm}^{3}$ anions. The adsorption process from a solution with a concentration of $0.001 \mathrm{~mol} / \mathrm{dm}^{3}$ takes place in three stages and is well described by the multiexponential equation of adsorption kinetics. The process of tartrate and citrate ion desorption after increasing the $\mathrm{pH}$ to 10 is irreversible, while the oxalate ions undergo significant desorption with the increasing $\mathrm{pH}$. The adsorption of oxalate ions decreases with the increasing $\mathrm{pH}$. This effect is weaker in the adsorption of citrate and tartrate ions. Ion adsorption studies were supplemented with the measurements of zeta potential, FTIR and particle distribution of hydroxyapatite particles.
\end{abstract}

Keywords: hydroxyapatite; adsorption; carboxylic acid ions

\section{Introduction}

Due to its properties, hydroxyapatite $\left[\mathrm{Ca}_{10}(\mathrm{OH})_{2}\left(\mathrm{PO}_{4}\right)_{6}\right](\mathrm{HAp})$ can be classified as a biocompatible and bioactive material, but due to its natural microporous structure, it is also well known as a good adsorbent, particularly for immobilization cations. HAp is capable of reversible exchange of hydroxyl ions by anions like $\mathrm{F}, \mathrm{Cl}$ or I ions [1]. HAp also adsorbs/exchanges some larger ions like carbonate, oxalate, citrate or tartrate. As HAp is a mineral compound of human bones and teeth and, on the other hand, the organic acids naturally occur in our diet, the interactions of both compounds can lead in our organism to, e.g., subsequent processes of adsorption, dissolution, precipitation and aggregation. Solutions that contain oxalate, citrate or tartrate salts can cause dissolution of hydroxyapatite but the mechanism of teeth surface etching by salts containing citrate ions is still not fully understood [2]. Hydroxyapatite, brushite and amorphous calcium phosphate play an important role in the heterogeneous nucleation of calcium oxalate monohydrate and the formation of "kidney stones" accumulated in the kidneys [3,4]. However, studies of the heterogeneous nucleation of calcium oxalate monohydrate were carried out in supersaturated solutions of calcium and oxalate ions to ensure crystal nucleation and growth of calcium oxalate [3].

In this paper, the comparison of the kinetic and static adsorption of oxalate, citrate and tartrate ions on hydroxyapatite was investigated using the ${ }^{14} \mathrm{C}$ radiolabeled acids from acid solutions of initial concentrations of 0.000001 and $0.001 \mathrm{~mol} / \mathrm{dm}^{3}$ and $\mathrm{pH}$ range from 6 to 11 . The adsorption measurements were complemented by the spectrometric, potentiometric titration of HAp suspensions and electrophoretic measurements. 


\section{Materials and Methods}

The carboxylic acid adsorption studies presented in this paper were carried out using a sample of hydroxyapatite purchased from Aldrich with a specific surface area of $101 \mathrm{~m}^{2} / \mathrm{g}$. The other used reagents were pure and were purchased from P.P.H. Polish Chemical Reagents Gliwice. Water with a specific conductivity $<0.05 \mu \mathrm{S} / \mathrm{cm}$ was used to prepare the solutions. The adsorption studies were carried out using the following solutions: $0.001 \mathrm{~mol} / \mathrm{dm}^{3} \mathrm{NaCl}, 0.001 \mathrm{~mol} / \mathrm{dm}^{3}$ oxalic acid, $0.001 \mathrm{~mol} / \mathrm{dm}^{3}$ citric acid, $0.001 \mathrm{~mol} / \mathrm{dm}^{3}$ tartaric acid.

The FTIR spectra of the sample were recorded using the Perkin-Elmer Spectrophotometer type 1725X. The specific surface area and porosity of the hydroxyapatite sample were studied by nitrogen the adsorption-desorption method. The particle size distribution was examined by static light scattering using Mastersizer 2000 Malvern UK. The physicochemical properties of hydroxyapatite surfaces groups were studied by means of electrophoretic measurements. The surface charge density and zeta potential were measured for the $0.001 \mathrm{~mol} / \mathrm{dm}^{3} \mathrm{NaCl}$ solutions as a function of $\mathrm{pH}$ and concentration of the oxalate anions ranged from 0.000001 to $0.001 \mathrm{~mol} / \mathrm{dm}^{3}$. The adsorption of oxalate, citrate and tartrate ions was estimated from the concentration of ions from solutions that was determined by the radioisotopic method using labeled ${ }^{14} \mathrm{C}$ of oxalic acid, citric acid and tartaric acid, respectively.

\section{Result and Discussion}

Studies of ion adsorption in the hydroxyapatite/aqueous electrolyte system due to the solubility of the hydroxyapatite are confined to the $\mathrm{pH}$ range of 6 to 11 . The speciation of ionic forms created as a result of oxalic acid dissociation as a function of $\mathrm{pH}$ indicates that mainly $\mathrm{C}_{2} \mathrm{O}_{4}{ }^{2-}$ ions are present in the $\mathrm{pH}$ range 6-11 [5]. The dominant forms of citrate ions below the range of $\mathrm{pH}$ 6-6.4 are the hydrogen citrate ions $\left(\mathrm{HCit}^{2-}\right)$ and above the range are the citrate anions $\left(\mathrm{Cit}^{3-}\right)$. However, in the $\mathrm{pH}$ range of 6 to 11, tartaric acid occurs in the form of tartrate anions [6].

\subsection{Kinetics of Oxalate Ion Adsorption at the Hydroxyapatite/0.001 mol/d $\mathrm{m}^{3} \mathrm{NaCl}$ Aqueous Solution Interface}

The rate of the ion adsorption in the hydroxyapatite/aqueous solution of electrolytes is described by the same equations as the rate of ion adsorption at the metal oxide/electrolyte.

The pseudo-first order equation depending on adsorption (a):

$$
\frac{d a}{d t}=k_{1}\left(a_{e q}-a\right)
$$

After integration the nonlinear form the above equation is:

$$
a=a_{e q}\left(1-e^{-k_{1} t}\right)
$$

where: $a_{e q}$-the equilibrium adsorption density, $a$-the adsorption density, $k_{1}$-the kinetics coefficient, $t$-the time.

The pseudo -second order nonlinear equation:

$$
a=\frac{a_{e q}^{2} k_{2} t}{1+a_{e q} k_{2} t}
$$

where: $a_{e q}$-the equilibrium adsorption density, $a$-the adsorption density, $k_{2}$-the kinetics coefficient, $t$-the time.

Multiexponential equation

$$
\frac{a}{a_{e q}}=1-\frac{\sum_{i+1}^{n} A_{i} \exp (-k, t)}{\sum_{i+1}^{n} A_{i}}=1-\frac{\sum_{i=1}^{n} A_{i} \exp (-k, t)}{1-A_{0}}=1-\sum_{i=1}^{n} \frac{A_{i}}{1-A_{0}} \exp \left(-k_{i} t\right)
$$


where: $a$-the adsorption density, $a_{e q}$-the equilibrium adsorption, $A_{0}$-the relative equilibrium concentration, $A_{i}$-describes the part of the $i$-th process characterized by the coefficient $k_{i}$.

However, due to the specific structure of hydroxyapatite crystal (presence of natural channels) [1] and the solubility of hydroxyapatite, the long-term study of adsorption reveals that slow adsorption proceeds after the fast adsorption stage [7]. If the kinetics of ion adsorption from solutions with an initial concentration of $0.000001 \mathrm{~mol} / \mathrm{dm}^{3}$ for $3 \mathrm{~h}$ was investigated, the pseudo-first or pseudo-second-order equations would fit the experimental data [8,9].

The kinetics of the oxalate ion adsorption of the initial concentrations 0.000001 and $0.001 \mathrm{~mol} / \mathrm{dm}^{3}$ at the hydroxyapatite $/ 0.001 \mathrm{~mol} / \mathrm{dm}^{3} \mathrm{NaCl}$ solution is depicted in Figures 1 and 2, respectively. As it can be seen from Figure 1, the adsorption of oxalate, citrate and tartrate ions after the 5 min hydroxyapatite contact with the electrolyte solution, as well as the $\mathrm{pH}$ of the suspension, are stable. The fitting adsorption data of oxalic and citric ions the using pseudo-first-order and the pseudo-second-order equations show that the latter gives almost the best fit [10]. However, the kinetics of the tartrate ion adsorption on hydroxyapatite from a solution with an initial concentration of $0.000001 \mathrm{~mol} / \mathrm{dm}^{3}$ is best fitted by the multiexponential equation [11]. As can be seen from Figure 1, the adsorption affinity of the anions of the tested acids for the hydroxyapatite surface is the highest for the oxalic anion ( $95 \%$ of the oxalate ions are adsorbed), lower for the tartrate anion ( $\sim 86 \%$ of the tartrate ions are adsorbed) and the lowest for the citrate ( $\sim 50 \%$ of the citrate ions are adsorbed). The adsorption affinity of carboxylic acid ions for the hydroxyapatite surface can be compared with the solubility of calcium salts of the above mentioned acids: the less soluble salt is calcium oxalate $\left(\mathrm{pK}_{\mathrm{so}}(\mathrm{CaOX}=8.63)\right.$ [12] the more soluble salt is calcium tartrate $\left(\mathrm{pK}_{\mathrm{so}}(\mathrm{CaTart}=6.11)[13]\right.$ and the preferred is calcium citrate $\left(\mathrm{pK}_{\mathrm{so}}\left(\mathrm{Ca}_{3} \mathrm{Cit}_{2}\right)=13.15\right)$ [14].

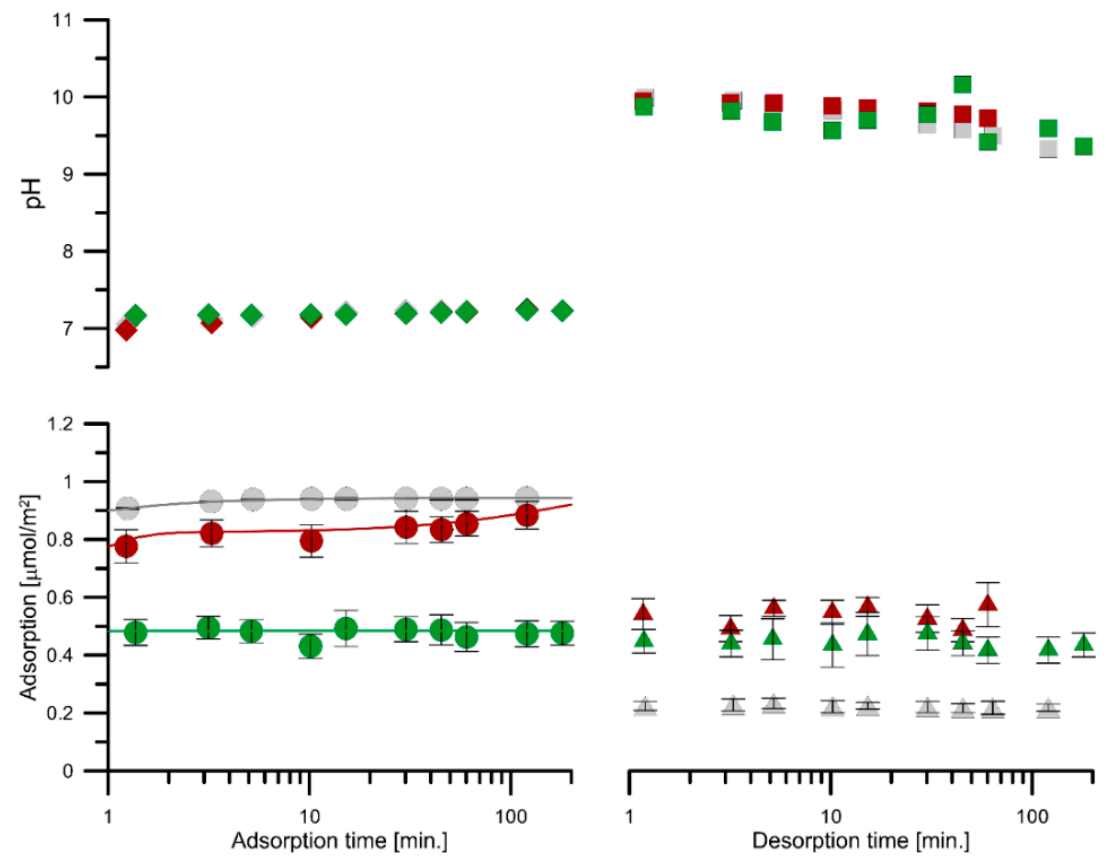

Figure 1. Kinetics of $\mathrm{pH}$ changes of suspension and carboxylic ion adsorption/desorption changes on hydroxyapatite from the carboxylic ion solution of the initial concentration $0.000001 \mathrm{~mol} / \mathrm{dm}^{3}$. Grey points denote the oxalic, green points denote citric, and ruby points denote tartrate ions. The black, green, and wine colored lines represent a fit with a pseudo-second-order kinetic equation for the adsorption kinetics of oxalate and citrate anions and multiexponential equation for tartrate anions, respectively. The parameters of adsorption fitting line are presented in Tables 1 and 2. 
Table 1. Parameters of the pseudo-first-order and the pseudo-second-order equations fitted to the data of adsorption kinetics of oxalate, citrate and tartrate ions from the solutions of the initial concentration $0.000001 \mathrm{~mol} / \mathrm{dm}^{3}$ on the hydroxyapatite.

\begin{tabular}{cccccccc}
\hline \multirow{2}{*}{ Ion } & $\begin{array}{c}\text { Concentration } \\
\mathbf{m o l} / \mathbf{d m}^{\mathbf{3}}\end{array}$ & \multicolumn{3}{c}{ Pseudo-First-Order } & \multicolumn{3}{c}{ Pseudo-Second-Order } \\
\cline { 3 - 8 } & $\mathbf{a}_{\mathbf{e}}$ & $\mathbf{k}_{\mathbf{1}}$ & $\mathbf{S S E}$ & $\mathbf{a}_{\mathbf{e}}$ & $\mathbf{k}_{\mathbf{2}}$ & $\mathbf{S S E}$ \\
\hline Oxalate & 0.0000001 & 0.939 & 2.707 & 0.00009 & 0.944 & 21.47 & 0.00003 \\
\hline Citrate & 0.0000001 & 0.483 & 3.464 & 0.0008 & 0.482 & 3936.9 & 0.0008 \\
\hline Tartrate & 0.0000001 & 0.852 & 2.221 & 0.0037 & 0.825 & 40423 & 0.0021 \\
\hline
\end{tabular}

Table 2. Parameters of the multiexponential equation fitted to the data of adsorption kinetics of oxalate, citrate and tartrate ions from the solutions of the initial concentration $0.000001 \mathrm{~mol} / \mathrm{dm}^{3}$ on the hydroxyapatite.

\begin{tabular}{cccccccccc}
\hline Ion & $\mathbf{a}_{\mathbf{e q}}$ & $\mathbf{A}_{\mathbf{0}}$ & $\mathbf{k}_{\mathbf{1}}$ & $\mathbf{A}_{\mathbf{1}}$ & $\mathbf{k}_{\mathbf{2}}$ & $\mathbf{A}_{\mathbf{2}}$ & $\mathbf{k}_{\mathbf{3}}$ & $\mathbf{A}_{\mathbf{3}}$ & $\mathbf{S S E}$ \\
\hline Tartrate & 0.974 & 0.355 & 2.574 & 0.222 & $5.31 \times 10^{-3}$ & 0.100 & 2.633 & 0.220 & 0.0006 \\
\hline
\end{tabular}
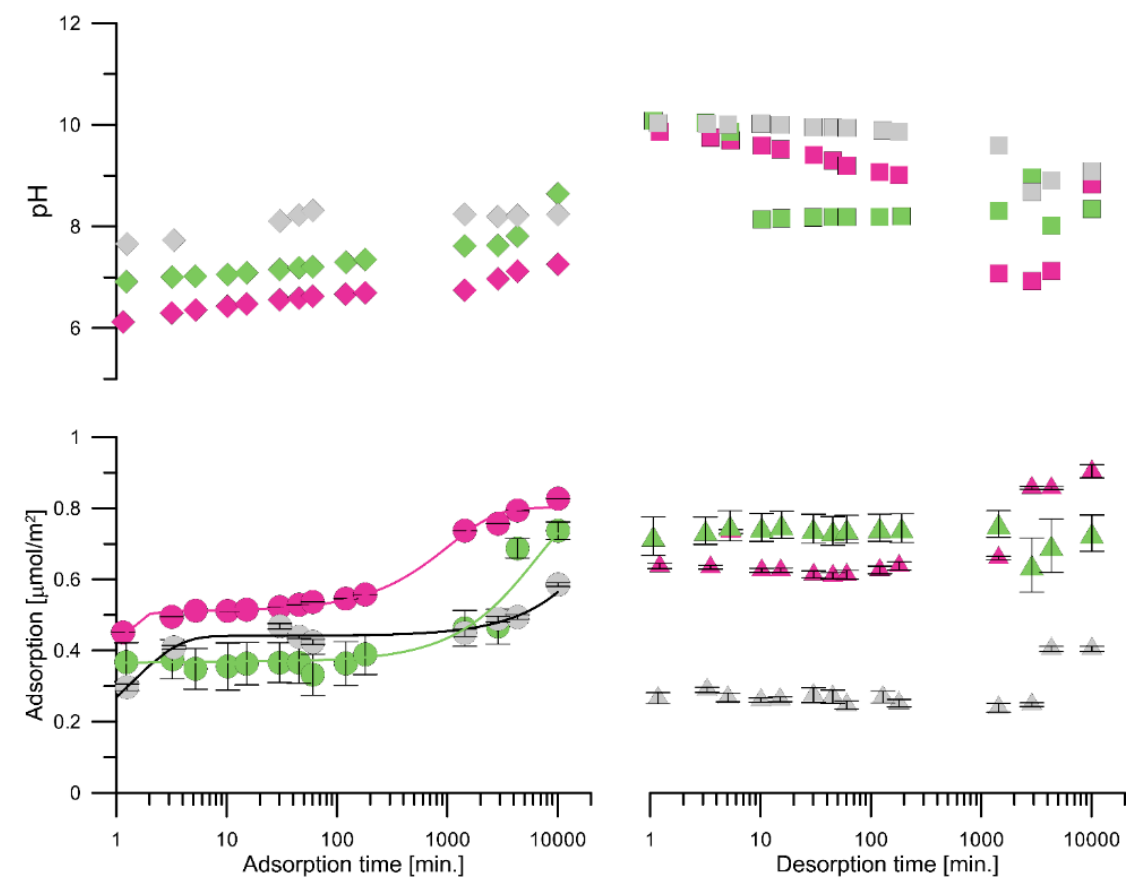

Figure 2. Kinetics of $\mathrm{pH}$ changes of the suspension and carboxylic ion adsorption changes on hydroxyapatite from the carboxylic ion solution of the initial concentration $0.001 \mathrm{~mol} / \mathrm{dm}^{3}$. The experimental data points: grey—oxalic ions, green—citric ions and wine color-tartaric ions. The black, green and wine colored lines represent multiexponential equation fitting the data of adsorption kinetics of oxalate, citrate and tartrate ions. The parameters of adsorption fitting line are presented in Table 3.

Table 3. Parameters of the multiexponential equation fitted to the data of adsorption kinetics of oxalate, citrate and tartrate ions from the solutions of the initial concentration $0.001 \mathrm{~mol} / \mathrm{dm}^{3}$ on the hydroxyapatite.

\begin{tabular}{cccccccccc}
\hline Ion & $\mathbf{a}_{\mathbf{e q}}$ & $\mathbf{A}_{\mathbf{0}}$ & $\mathbf{k}_{\mathbf{1}}$ & $\mathbf{A}_{\mathbf{1}}$ & $\mathbf{k}_{\mathbf{2}}$ & $\mathbf{A}_{\mathbf{2}}$ & $\mathbf{k}_{\mathbf{3}}$ & $\mathbf{A}_{\mathbf{3}}$ & $\left(\frac{\boldsymbol{a}_{\text {exp }}-\boldsymbol{a}_{\text {calc }}}{\boldsymbol{a}_{\text {exp }}}\right)^{\mathbf{2}}$ \\
\hline Oxalate & 1.106 & 0.142 & 0.76 & 0.058 & $2.05 \times 10^{-5}$ & 0.516 & 0.725 & 0.220 & 0.006 \\
\hline Citrate & 0.819 & 0.216 & 1.04 & 0.01 & 17.2 & 0.342 & 0.00016 & 0.432 & 0.062 \\
\hline Tartrate & 0.802 & 0.670 & 2.295 & 0125 & $9.66 \times 10^{-4}$ & 0.120 & 2.283 & 0.220 & 0.0016 \\
\hline
\end{tabular}


After $120 \mathrm{~min}$, the $\mathrm{pH}$ of the suspension was changed to 10 and the kinetics of desorption of carboxylic acid anions was studied (lower right part of Figure 1). As can be seen, the change in $\mathrm{pH}$ caused significant desorption of oxalate ions ( $23 \%$ of the ions remained on the surface), while in the case of citrate ions, this was around $43 \%$, and for tartrate ions, around $53 \%$. However, after a long period of conditioning (1440 $\mathrm{min}$ ), as a result of the reaction in suspension in the presence of oxalate ions, the $\mathrm{pH}$ dropped to the value of 8.3, which resulted in an increase in the adsorption of oxalate ions to $71 \%$. In the case of the tartrate and citrate ions, the decrease in $\mathrm{pH}$ after this conditioning period was not large and thus the increase in adsorption was of the order of $1 \%$.

For the initial concentration of oxalate, tartrate and citrate ions of $0.001 \mathrm{~mol} / \mathrm{dm}^{3}$, in the course of kinetics, three stages can be distinguished. The first stage in the first $5 \mathrm{~min}$ shows a rapid increase in adsorption ( $62 \%$ oxalate, $52 \%$ tartrate and $35 \%$ citrate). In the second stage, the $\mathrm{pH}$ increase and the anion adsorption increase by several percent are observed within $200 \mathrm{~min}$. In the third stage, up to $10,080 \mathrm{~min}$, there is a greater increase in the anion adsorption again, to the value of $95 \%$ oxalate ions, $83 \%$ tartrate ions and $74 \%$ citrate ions. The experimental adsorption data depicted in Figure 2 are well fitted using also the multiexponential model. Such three-stage adsorption may be the result of a dissolution-precipitation mechanism [7] adsorption at the interface or intraparticle diffusion [15]. Taking into account the anisotropic ion radiation of Van der Waals of tartrate ions $\left(\mathrm{a}_{\mathrm{x}}=0.3 \mathrm{~nm}, \mathrm{a}_{\mathrm{y}}=0.28\right.$, $\left.\mathrm{a}_{\mathrm{z}}=2.41 \mathrm{~nm}\right)$ and citrate ions $\left(\mathrm{a}_{\mathrm{x}}=0.33 \mathrm{~nm}, \mathrm{a}_{\mathrm{y}}=0.29, \mathrm{a}_{\mathrm{z}}=2.81 \mathrm{~nm}\right)[16]$, it can be assumed that only in the case of type II channels (0.3-0.45 nm diameter) [17] is diffusion of these ions and subsequent ion exchange possible.

To describe the mechanism of slow uptake of carboxylic acid ions, particle size analysis of hydroxyapatite in the presence and absence of carboxylic acid ions was conducted.

After 10,080 min, the $\mathrm{pH}$ of the suspension was changed to 10 and the kinetics of desorption of carboxylic acid anions was observed (lower right part of Figure 2). Increasing the $\mathrm{pH}$ of the suspension causes the absorption of oxalate anions to decrease from $59 \%$ to $27 \%$. As time passes, the $\mathrm{pH}$ of the suspension decreases due to the dissolution reaction and the amount of adsorbed oxalate anions decreases by $\sim 2 \%$. After $3000 \mathrm{~min}$, the $\mathrm{pH}$ drops further and the adsorption of oxalate ions increases to $41 \%$. The course of adsorption of tartrate ions after changing the $\mathrm{pH}$ of the suspension from 7.2 to 9.9 is similar to that of oxalate ions. However, the decrease in adsorption is smaller than for oxalate ions (adsorption reduces from $83.5 \%$ to $64 \%$ ). After $2880 \mathrm{~min}$, the adsorption increases to $86.6 \%$, and after $10,080 \mathrm{~min}$, the adsorption value is $91 \%$. However, in the case of citrate ions, increasing the $\mathrm{pH}$ does not reduce adsorption. This is probably due to the fact that the $\mathrm{pH}$ of the suspension drops to 8.1 after $10 \mathrm{~min}$.

\subsection{Study of the Carboxylic Acid Ion Adsorption at the HAp/Aqueous Electrolyte Interface as a Function of $p H$}

The uptake of ions from the solution due to the interactions of ions with the hydroxyapatite surface may result in the adsorption of ions on the active sites of the hydroxyapatite surface $\left(\mathrm{Ca}^{2+}\right.$, $-\mathrm{OH},=\mathrm{HPO}_{4}$ ), due to the exchange of ions from the solution with those of the hydroxyapatite crystal lattice and/or the processes of hydroxyapatite dissolution and recrystallization of the new phase [18]. The above-mentioned mechanisms, depending on the $\mathrm{pH}$ and ion concentration, may sometimes occur simultaneously. The dissolution and recrystallization mechanisms usually take place at high concentrations of these ions in solution.

The adsorption of oxalate, citrate and tartrate ions from the solution of the initial concentrations $0.000001 \mathrm{~mol} / \mathrm{dm}^{3}$ and $0.001 \mathrm{~mol} / \mathrm{dm}^{3}$ as a function of $\mathrm{pH}$ on hydroxyapatite is depicted in Figures 3 and 4, respectively. As it can be seen, the adsorption of oxalate ions from the solution of the initial concentration $0.000001 \mathrm{~mol} / \mathrm{dm}^{3}$, shown in Figure 3, decreases with the increase in $\mathrm{pH}$ of the solution, from $95 \%$ at $\mathrm{pH}=6.8$ to $16.5 \%$ at $\mathrm{pH}=10$. This graph is similar to the one depicting the adsorption of ions at the metal oxide/electrolyte solution interface that proceeds via exchange with surface of the hydroxyl ions. The tartrate ion adsorption also decreases with the increasing $\mathrm{pH}$, but to a much smaller extent, from $74 \%$ at $\mathrm{pH}=7.2$ to $48 \%$ at $\mathrm{pH}=10.7$. On the other hand, the adsorption 
of citrate ions is the lowest in the tested $\mathrm{pH}$ range and it decreases from $33 \%$ at $\mathrm{pH}=7$ to $15 \%$ at $\mathrm{pH}$ $=9.85$. The presented relations show that the adsorption of oxalate anions in the range of $\mathrm{pH} 6-8.3$ is characterized by the highest adsorption affinity for the hydroxyapatite surface, but above this $\mathrm{pH}$ range, the tartrate ion is more strongly adsorbed. On the other hand, in the whole $\mathrm{pH}$ range, the citrate ion is the most weakly adsorbed. The presented relationships of adsorption of oxalic and citric acid anions as a function of $\mathrm{pH}$ are in good agreement with the studies by Wei et al. [19].

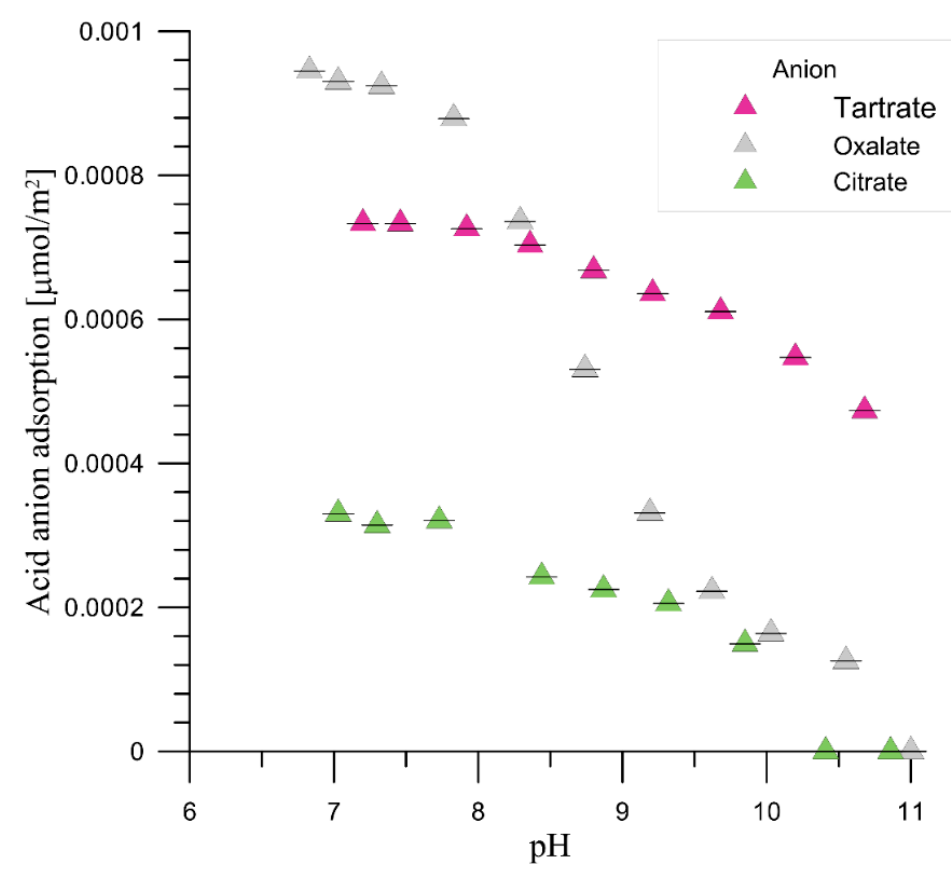

Figure 3. Oxalate, citrate and tartrate ion adsorption in the hydroxyapatite $/ 0.001 \mathrm{~mol} / \mathrm{dm}^{3} \mathrm{NaCl}$ solution system as a pH function. The initial concentration of oxalate, citrate or tartrate ions was $0.000001 \mathrm{~mol} / \mathrm{dm}^{3}$.

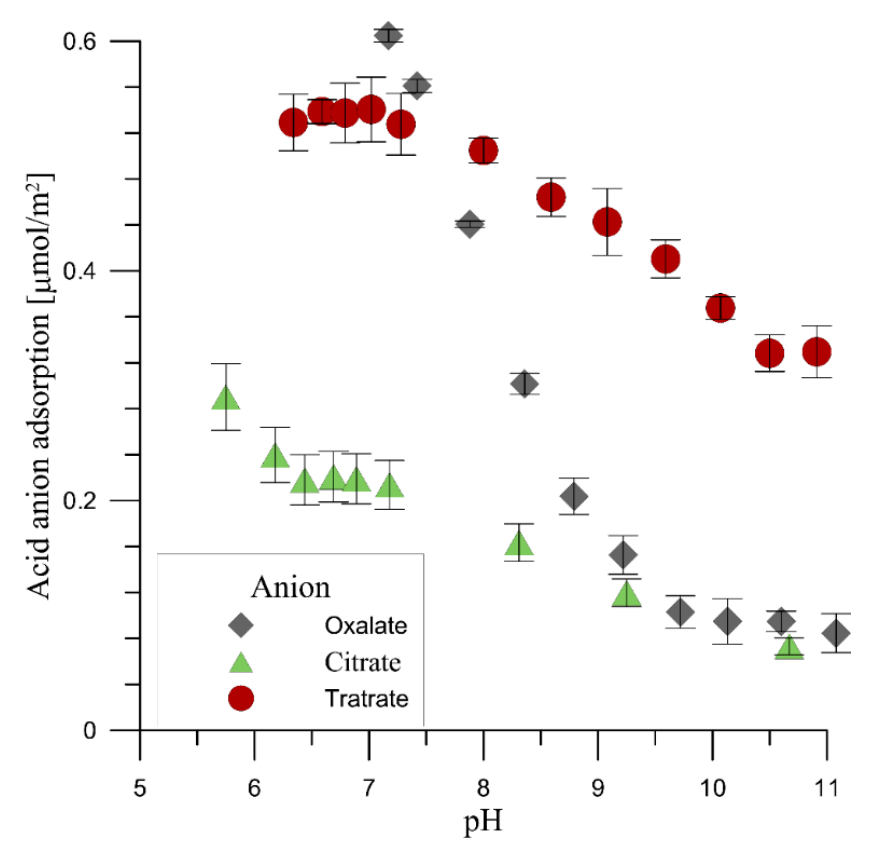

Figure 4. Oxalate, citrate and tartrate ion adsorption in the hydroxyapatite $/ 0.001 \mathrm{~mol} / \mathrm{dm}^{3} \mathrm{NaCl}$ solution system as a $\mathrm{pH}$ function. The initial concentration of oxalate, citrate or tartrate ions was $0.001 \mathrm{~mol} / \mathrm{dm}^{3}$. 
The comparison of the adsorption of oxalate, citrate and tartrate ions from the solution of the initial concentration of $0.001 \mathrm{~mol} / \mathrm{dm}^{3}$ as a function of $\mathrm{pH}$ in the hydroxyapatite $/ 0.001 \mathrm{~mol} / \mathrm{dm}^{3}$ aqueous $\mathrm{NaCl}$ solution is presented in Figure 4. The oxalate ion adsorption decreases significantly with the $\mathrm{pH}$ increase, i.e., $61 \%$ at $\mathrm{pH}=7.2$ to 9.6 at $\mathrm{pH}=10.6$, whereas the adsorption of tartrate ions in the tested $\mathrm{pH}$ range changes less, from $53 \%$ at $\mathrm{pH}=6.34$ to $33 \%$ at $\mathrm{pH}=10.9$. The adsorption of citrate ions also decreases as the $\mathrm{pH}$ increases, i.e., $29 \%$ at $\mathrm{pH}=5.75$ to $7.4 \%$ at $\mathrm{pH} 10.67$. Comparing the surface concentration of different adsorption sites on the hydroxyapatite surface, i.e., $\mathrm{N}_{\mathrm{Ca}}=7.5 \mu \mathrm{mol} / \mathrm{m}^{2}$, $\mathrm{N}_{\mathrm{PO} 4}=5.0 \mu \mathrm{mol} / \mathrm{m}^{2}$ [20] and $\mathrm{N}_{\mathrm{OH}}=2.5 \mu \mathrm{mol} / \mathrm{m}^{2}$ [21], with the adsorption of the tested carboxylic acid anions, it can be seen that the adsorption of these anions was much lower than the formal monolayer of each of the above-mentioned in adsorption sites. Such adsorption is dependent on carboxylic acid ions vs. $\mathrm{pH}$ results from the exchange of phosphate ions from the hydroxyapatite crystal.

The effect of the adsorption of carboxylic acid ions onto hydroxyapatite on the zeta potential is depicted in Figure 5. As follows, the presence of carboxylic acid ions at the concentration $0.001 \mathrm{~mol} / \mathrm{dm}^{3}$ results in a decrease in the zeta potential in the $\mathrm{pH}$ range of 5 to 9 . The most significant effect is observed for the $\mathrm{pH}$ range of 6 to 7 , where the adsorption of carboxylic acid ions on the hydroxyapatite is the highest. The effect of zeta potential decrease by carboxylic acid ion adsorption is caused by the decrease in the substitution of the phosphate group on the hydroxyapatite surface by the carboxylic acid ions that exhibit more acidic properties than those of phosphate.

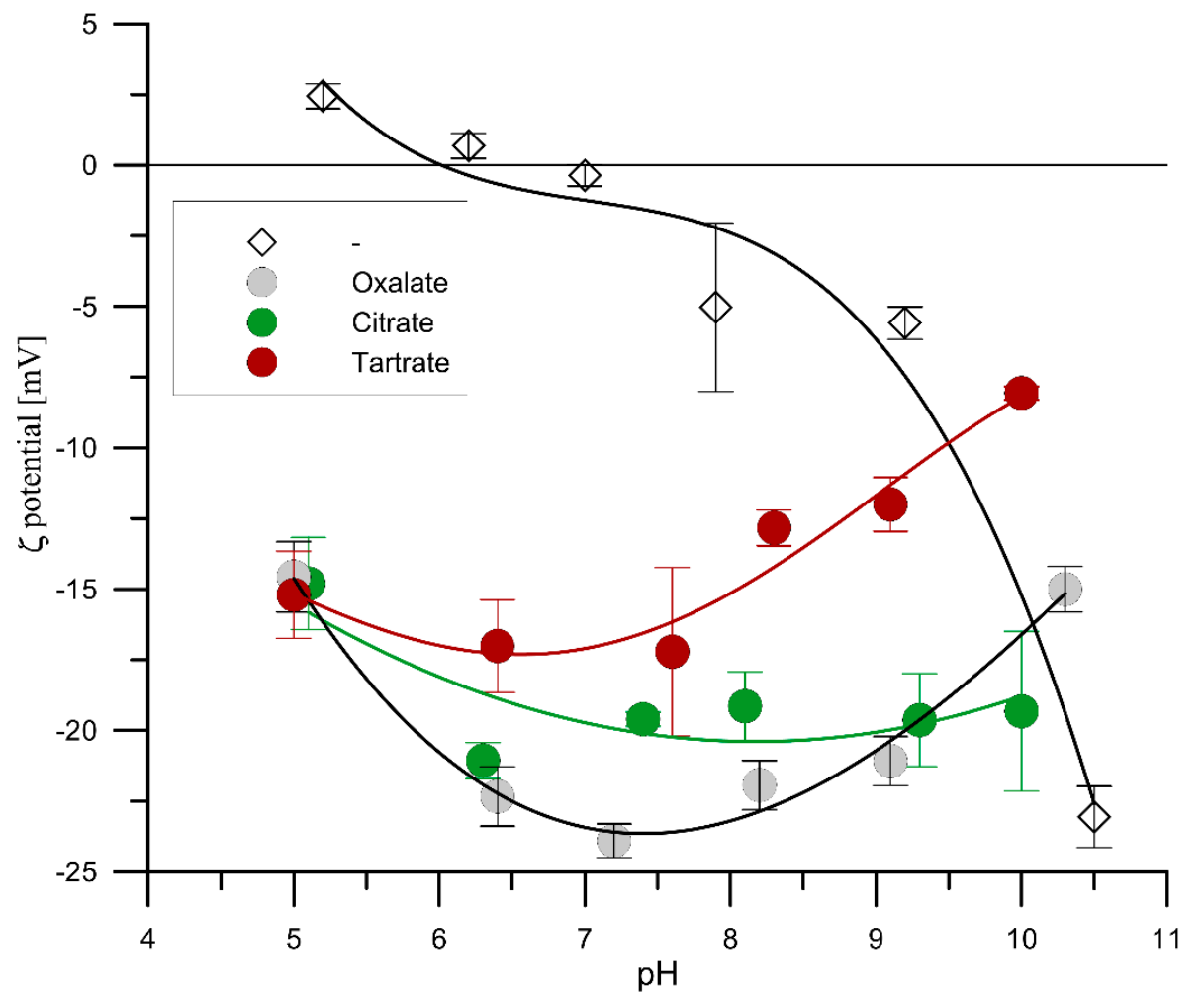

Figure 5. Zeta potential as a function of $\mathrm{pH}$ in $0.001 \mathrm{~mol} / \mathrm{dm}^{3}$ (open points) and $0.001 \mathrm{~mol} / \mathrm{dm}^{3}$ oxalate ions (grey closed circle), citrate (green closed circle) and tartrate (wine-colored closed circle).

Figure 6 presents the FTIR transmission spectra of the hydroxyapatite sample and the samples of hydroxyapatite conditioned in $0.001 \mathrm{~mol} / \mathrm{dm}^{3}$ oxalic, citric or tartaric acid solutions. The analysis of the characteristic bands of the hydroxyapatite sample (HAp spectrum) indicates the presence of the $\mathrm{OH}$ group (characteristic bands at the wavenumber 3572 and $631 \mathrm{~cm}^{-1}$ that can be assigned to the stretching mode $v_{\mathrm{s}}$ and the vibration mode $v_{\mathrm{L}}$, respectively, and at $1630 \mathrm{~cm}^{-1}$ to the bending mode of water molecule [22]; phosphate groups bands at the wavenumber 1093, 1033, $962 \mathrm{~cm}^{-1}$ assigned to the vibrations of these groups). Moreover, the presence of the bands characteristic of the carbonate 
groups at the wavenumbers of 1419 and $1453 \mathrm{~cm}^{-1}$ can be seen. Their presence may be related to the chemisorption of carbon dioxide on hydroxyapatite during synthesis, storage and experiments [23,24].

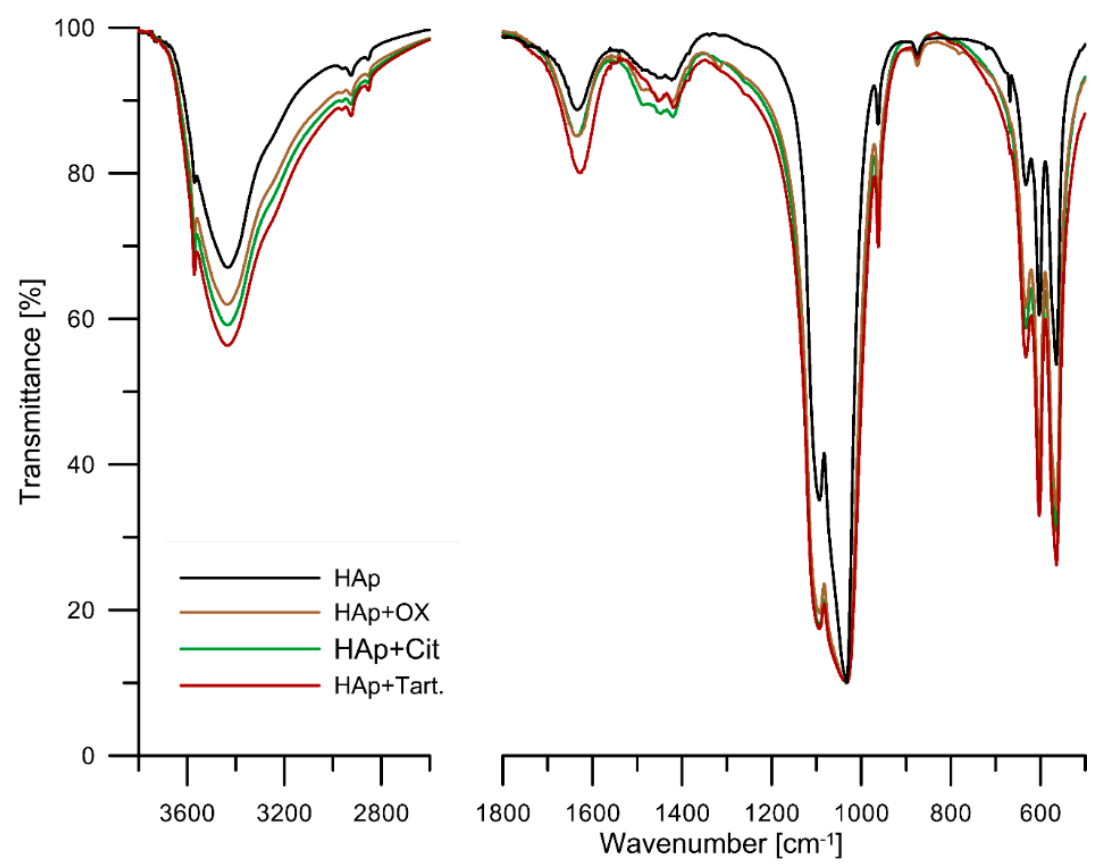

Figure 6. FTIR transmittance spectrum of hydroxyapatite (HAp), hydroxyapatite with adsorbed oxalic ions $(\mathrm{HAp}+\mathrm{OX})$, hydroxyapatite with adsorbed citrate ions $(\mathrm{HAp}+\mathrm{Cit})$, hydroxyapatite with adsorbed oxalic ions (HAp + OX) and hydroxyapatite with adsorbed tatrate ions (HAp + Tart).

The FTIR spectrum of the samples conditioned in the $0.001 \mathrm{~mol} / \mathrm{dm}^{3}$ carboxylic acid solutions is richer, but a number of bands overlap with the characteristic HAp bands to show the presence of acid anions from the FTIR HAp spectrum. The FTIR spectra of hydroxyapatite samples conditioned in acid solutions were subtracted and the spectra subtracted for these samples are shown in Figure 7. As can be seen in the spectrum, there are a number of bands characteristic of calcium oxalate, citrate or tartrate [25-30]. The wavenumbers corresponding to the individual bands and the bands assigned to them, on the basis of the spectra for salts or calcium complexes, are presented in Table 3. The FTIR spectra presented in Figure 7 and the data in Table 4 indicate the chemisorption of oxalate, citrate and tartrate anions on the hydroxyapatite surface.

Table 4. The wavenumbers $\left(\mathrm{cm}^{-1}\right)$ and assignments for oxalate, citrate and tartrate ions on the hydroxyapatite surface.

\begin{tabular}{|c|c|c|c|c|}
\hline Oxalate & Citrate & Tartrate & Assignment & Ref. \\
\hline 560 & 560 & 559 & Ca-O mode & {$[28,30]$} \\
\hline 603 & 602 & 602 & Ca-O mode & {$[28,30]$} \\
\hline 962 & 962 & 962 & Ca-O mode & {$[28,30]$} \\
\hline 1012 & 1010 & 1008 & $v(\mathrm{C}-\mathrm{O})$ & {$[30]$} \\
\hline 1083 & 1083 & 1083 & $\begin{array}{l}\text { Out of plane } \mathrm{OH} \\
\text { deformation }\end{array}$ & [27] \\
\hline 1120 & 1120 & 1122 & $\delta(\mathrm{C}-\mathrm{H})+\pi(-\mathrm{C}-\mathrm{H})$ & [30] \\
\hline 1316 & & & $\mathrm{OH}$ plane bending & [30] \\
\hline 1420 & 1420 & 1413 & $v_{\mathrm{s}}(\mathrm{COO}-)$ & {$[25,29]$} \\
\hline 1449 & 1449 & 1456 & $v\left(\mathrm{CO}_{3}{ }^{2-}\right)$ & [22] \\
\hline 1655 & 1655 & 1618 & $v_{\text {as }}(\mathrm{COO}-)$ & {$[25,29]$} \\
\hline 3571 & 3571 & 3571 & $\mathrm{OH}$ stretch & [28] \\
\hline
\end{tabular}

$v_{\mathrm{s}}$-the symmetric stretching, $v_{\mathrm{a}}$-the asymmetric stretching, $v$-the stretching, $\pi$-the wagging, $\delta$ - the bending. 


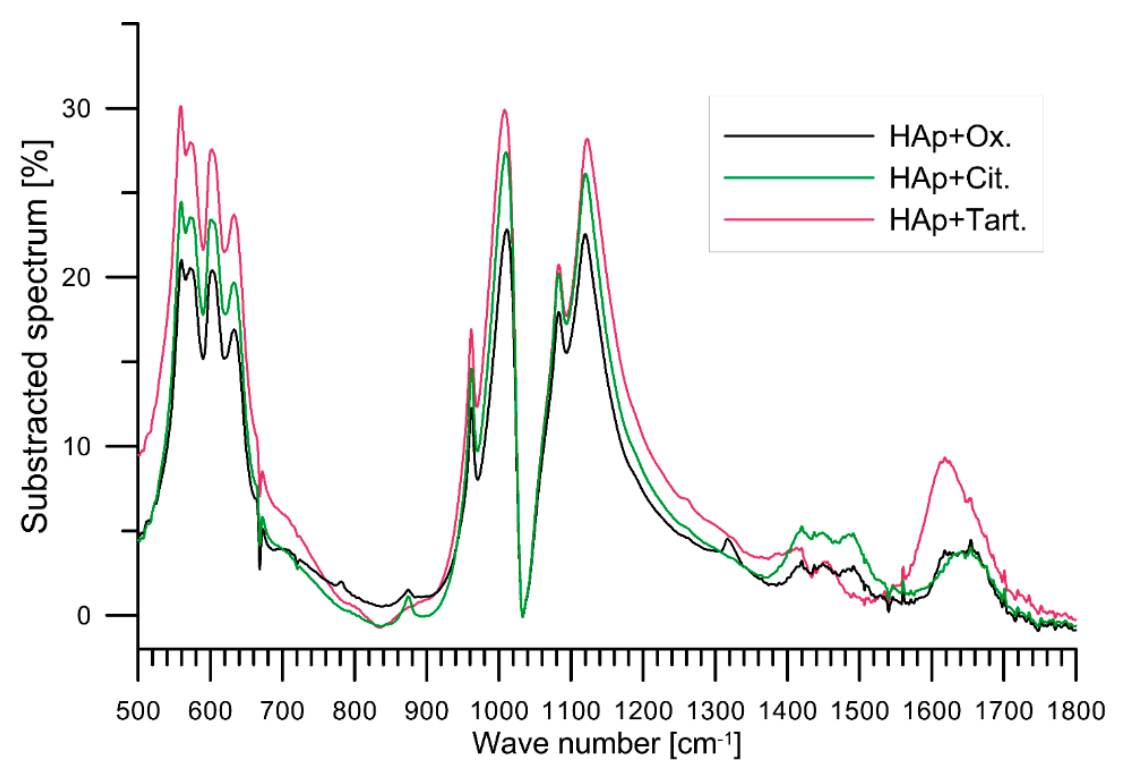

Figure 7. Comparison of the subtracted FTIR spectra of tartrate, citrate and oxalate ions adsorbed on hydroxyapatite.

Figures 8 and 9 show the volume particle distributions of the conditioned hydroxyapatite samples in solutions of the $0.001 \mathrm{~mol} / \mathrm{dm}^{3} \mathrm{NaCl}+0.001 \mathrm{~mol} / \mathrm{dm}^{3}$ of the tested carboxylic acids. For comparison, Figure 8 shows the particle size distribution of the conditioned hydroxyapatite sample in the $0.001 \mathrm{~mol} / \mathrm{dm}^{3} \mathrm{NaCl}$ solution (black triangles). As can be seen, the distribution of hydroxyapatite particles in the case of its conditioning in the solution of $0.001 \mathrm{~mol} / \mathrm{dm}^{3} \mathrm{NaCl}$ solution and in a solution of the $0.001 \mathrm{~mol} / \mathrm{dm}^{3} \mathrm{NaCl}$ containing tartrate ions with an initial concentration of $0.001 \mathrm{~mol} / \mathrm{dm}^{3}$ is similar, and it has a dimodal character. Most of the particles ( $95 \%)$ have diameters ranging from 0.4 to $7 \mu \mathrm{m}$, while the other smaller fractions range from 7 to $20 \mu \mathrm{m}$. In the case of hydroxyapatite conditioning in the solution containing oxalate and citric ions, after 14 days of conditioning, the decomposition is trimodal; the first fraction is in the range of 0.5 to $7 \mu \mathrm{m}$ ( $\sim 94 \%$ of particles), the second $7-20 \mu \mathrm{m}(\sim 4 \%$ of particles) and the third from 20 to $200 \mu \mathrm{m}(\sim 2 \%$ particles). The particle size distribution of hydroxyapatite conditioned for 14 days in conditioning the solution of $0.001 \mathrm{~mol} / \mathrm{dm}^{3}$ of citric acid is also trimodal: the first fraction ranges from 0.5 to $7 \mu \mathrm{m}$ ( $\sim 91 \%$ of particles), the second one $7-20 \mu \mathrm{m}$ ( $\sim 3 \%$ of particles) and the third from 20 to $200 \mu \mathrm{m}$ ( $\sim 6 \%$ particles). The presented HAp particle distributions in the acid solutions do not indicate the formation of a separate bulk phase (calcium carboxylates).

On the other hand, the presence of large particles may indicate the phenomenon of aggregation of smaller particles in the case of conditioning in the solution of oxalic and citric acids Figure 9; however, the errors characterizing the share of a given fraction indicate the instability of these aggregates (they are broken down and aggregated under the flow and ultrasound conditions). Measurements of the particle size distribution of hydroxyapatite in the carboxylic acid solutions do not exclude the process of surface precipitation, as a result of which, statistically, a layer with a thickness of several hundred of nanometers could be formed on the surface of the tested hydroxyapatite sample, but it is below the measurement capabilities of this method. 


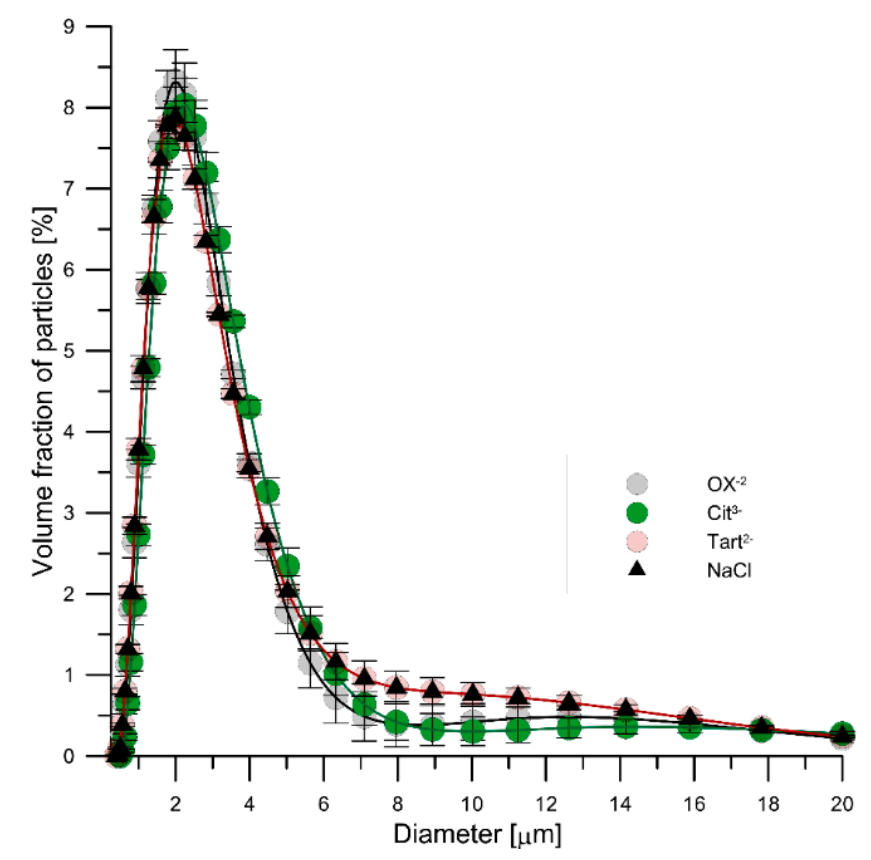

Figure 8. Comparison of the volume particle size distribution of the hydroxyapatite samples conditioned for 14 days in the solution of $0.001 \mathrm{~mol} / \mathrm{dm}^{3} \mathrm{NaCl}$ (black triangle), HAp in the solution with the $0.001 \mathrm{~mol} / \mathrm{dm}^{3} \mathrm{NaCl}+0.001 \mathrm{~mol} / \mathrm{dm}^{3}$ oxalate ions (grey circle), HAp in the solution with the $0.001 \mathrm{~mol} / \mathrm{dm}^{3} \mathrm{NaCl}+0.0001$ citrate ions (geen circle) and HAp in the solution containing $0.001 \mathrm{~mol} / \mathrm{dm}^{3}$ $\mathrm{NaCl}+0.001 \mathrm{~mol} / \mathrm{dm}^{3}$ tartrate ions.

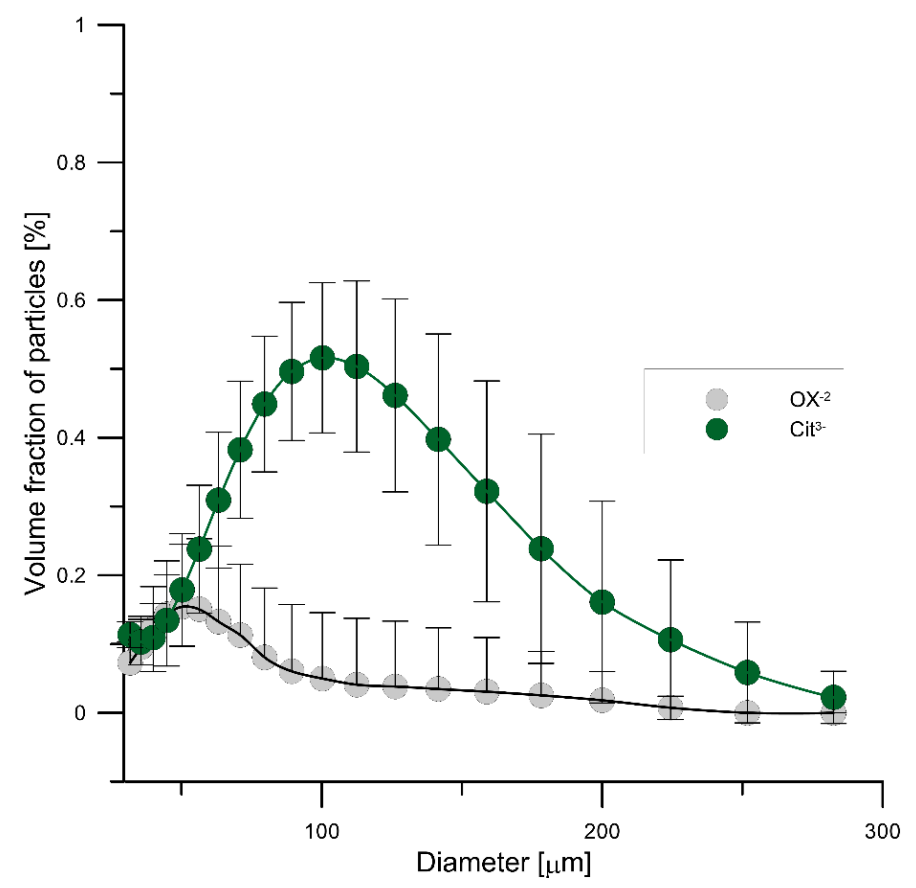

Figure 9. Particle size distribution of the hydroxyapatite samples conditioned for 14 days in a solution with $0.001 \mathrm{~mol} / \mathrm{dm}^{3} \mathrm{NaCl}+0.001 \mathrm{~mol} / \mathrm{dm}^{3}$ oxalate ions (grey circle), $\mathrm{HAp}$ of $0.001 \mathrm{~mol} / \mathrm{dm}^{3} \mathrm{NaCl}+$ $0.0001 \mathrm{~mol} / \mathrm{dm}^{3}$ citrate ions (green circle).

\section{Conclusions}

The mechanism of di- and tricarboxylic acid adsorption from the aqueous solutions on the hydroxyapatite is complicated due to the variety of reactions taking place in the system as a function 
of $\mathrm{pH}$ and interaction time. The reaction kinetics of oxalate and citrate ions from a dilute solution with the post concentration of $0.00001 \mathrm{~mol} / \mathrm{dm}^{3}$ is well matched with the pseudo-first-order equation. On the other hand, the kinetics of oxalate, citrate and tartrate ion reactions from the solutions with the initial concentration of $0.001 \mathrm{~mol} / \mathrm{dm}^{3}$ is more complex. There are three stages of adsorption at the time, and such a process is well-adjusted by the multiexponential equation.

The kinetics of desorption of carboxylic acid anions is rapid due to the $\mathrm{pH}$ increasing to 10 . An increase in $\mathrm{pH}$ causes significant desorption of oxalate ions, while citrate and tartrate anions are slightly desorbed. This may indicate that the oxalate ions replace the hydroxyl groups in hydroxyapatite, while the tartrate and citrate ions are phosphate groups.

The dependence of the adsorption of carboxylic acid anions on the $\mathrm{pH}$ of hydroxyapatite is strong for the oxalate anions and weaker for the tartrate and citrate anions. On the other hand, below $\mathrm{pH}=8.3$, at the initial concentration of $0.000001 \mathrm{~mol} / \mathrm{dm}^{3}$, the oxalate anion shows the highest adsorption affinity for hydroxyapatite and citrate the weakest. Above $\mathrm{pH} \mathrm{8.3,} \mathrm{the} \mathrm{tartrate} \mathrm{anion} \mathrm{adsorbs} \mathrm{most} \mathrm{strongly.}$ From the solution of the initial concentration of $0.001 \mathrm{~mol} / \mathrm{dm}^{3}$, below $\mathrm{pH}=7.5$, the oxalate ions exhibit the highest adsorption affinity, but above the tartrate ions.

The studies of the effect of adsorption of carboxylic acid anions on the dependence of the zeta potential of hydroxyapatite as a function of $\mathrm{pH}$ indicate that the adsorption of the above-mentioned anions increases the acidic nature of the hydroxyapatite surface.

The FTIR spectra of hydroxyapatite samples with the adsorbed ions of oxalic, citrate and tartaric acids showed the presence of characteristic bands for the calcium salts of these acids and indicate the chemisorption of these anions.

Author Contributions: Conceptualization, W.J.; methodology, formal analysis, and investigation, E.S.; resources, W.J.; data curation, W.J.; writing-original draft preparation, W.J.; writing-review and editing, E.S.; E.S.; supervision, W.J. All authors have read and agreed to the published version of the manuscript.

Funding: This research received no external funding.

Conflicts of Interest: The authors declare no conflict of interest.

\section{References}

1. Madhavi, S.; Ferraris, C.; White, T.J. Synthesis and crystallization of macroporous hydroxyapatite. J. Solid State Chem. 2005, 178, 2838-2845. [CrossRef]

2. Misra, D.N. Interaction of some alkali metal citrates with hydroxyapatite: Ion-exchange adsorption and role of charge balance. Colloids Surfaces A: Physicochem. Eng. Asp. 1998, 141, 173-179. [CrossRef]

3. Ebrahimpour, A.; Perez, L.; Nancollas, G.H. Induced Crystal Growth of Calcium Oxalate Monohydrate at Hydroxyapatite Surfaces. The Influence of Human Serum Albumin, Citrate, and Magnesium. Langmuir 1991, 7, 511-583. [CrossRef]

4. Xie, B.; Halter, T.J.; Borah, B.M.; Nancollas, G.H. Aggregation of Calcium Phosphate and Oxalate Phases in the Formation of Renal Stones. Cryst. Growth Des. 2015, 15, 204-211. [CrossRef] [PubMed]

5. Janusz, W.; Matysek, M. Coadsorption of $\mathrm{Cd}(\mathrm{II})$ and oxalate ions at the TiO2/electrolyte solution interface. J. Colloid Interface Sci. 2006, 296, 22-29. [CrossRef] [PubMed]

6. Rajković, M.B.; Novaković, I.D.; Petrović, A. Determination of Titratable Acidity in White Wine. J. Agric. Sci. Belgrade 2007, 52, 169-184. [CrossRef]

7. Valsami-Jones, E.; Ragnarsdottir, K.V.; Putnis, A.; Bosbach, D.; Kemp, A.J.; Cressey, G. The dissolution of apatite in the presence of aqueous metal cations at pH 2-7. Chem. Geol. 1998, 151, 215-233. [CrossRef]

8. Sheha, R.R. Sorption behavior of Zn(II) ions on synthesized hydroxyapatites. J. Colloid Interface Sci. 2007, 310, 18-26. [CrossRef]

9. Pan, X.; Wang, J.; Zhang, D. Sorption of cobalt to bone char: Kinetics, competitive sorption and mechanism. Desalination 2009, 249, 609-614. [CrossRef]

10. Marczewski, A.W. Kinetics and equilibrium of adsorption of organic solutes on mesoporous carbons. Appl. Sur. Sci. 2007, 253, 5818-5826. [CrossRef] 
11. Derylo-Marczewska, A.; Marczewski, A.W.; Winter, S.; Sternik, D. Studies of adsorption equilibria and kinetics in the systems: Aqueous solution of dyes-mesoporous carbons. Appl. Sur. Sci. 2010, 256, 5164-5170. [CrossRef]

12. CRC. Handbook of Chemistry and Physics, 84th ed.; Linde, D.R., Ed.; CRC Press: Boca Raton, FA, USA, 2003.

13. Gácsi, A.; Kutus, B.; Csendes, Z.; Faragó, T.; Peintler, G.; Pálinkó, I.; Sipos, P. Calcium L-tartrate complex formation in neutral and in hyperalkaline aqueous solutions. Dalton Trans. 2016, 45, 17296-17303. [CrossRef] [PubMed]

14. Vavrusova, M.; Garcia, A.C.; Danielsena, B.P.; Skibsted, L.H. Spontaneous supersaturation of calcium citrate from simultaneous isothermal dissolution of sodium citrate and sparingly soluble calcium hydroxycarboxylates in water. RSC Adv. 2017, 7, 3078-3088. [CrossRef]

15. Qadeer, R. Kinetic models applied to erbium adsorption on activated charcoal from aqueous solutions. J. Radioanal. Nucl. Chem. 2013, 295, 1051-1055. [CrossRef]

16. Parsons, D.F.; Ninham, B.W. Ab Initio Molar Volumes and Gaussian Radii. J. Phys. Chem. A 2009, 113, 1141-1150. [CrossRef]

17. Solhya, A.; Amera, W.; Karkourib, M.; Tahirb, R.; El Bouarib, A.; Fihri, A.; Bousminaa, M.; Zahouilya, M. Bi-functional modified-phosphate catalyzed the synthesis of (EE)-bis(benzylidene)-cycloalkanones: Microwave versus conventional-heating. J. Mol. Cat. A Chem. 2011, 336, 8-15. [CrossRef]

18. Vega, E.D.; Narda, G.E.; Ferretti, F.H. Adsorption of citric acid from dilute aqueous solutions by hydroxyapatite. J. Colloid Interface Sci. 2003, 268, 37-42. [CrossRef]

19. Wei, W.; Zhang, X.; Cui, J.; Wei, Z. Interaction between low molecular weight organic acids and hydroxyapatite with different degrees of crystallinity. Colloids and Surfaces A: Physicochem. Eng. Aspects 2011, 392, 67-75. [CrossRef]

20. Kukura, M.; Bell, L.C.; Posner, A.M.; Quirk, J.P. Radioisotope determination of the surface concentrations of calcium and phosphorus on hydroxylapatite in aqueous solution. J. Phys. Chem. 1972, 76, 900-908. [CrossRef]

21. Skartsila, K.; Spanos, N. Surface characterization of hydroxyapatite: Potentiometric titrations coupled with solubility measurements. J. Colloid Interface Sci. 2007, 308, 405-412. [CrossRef]

22. Koutsopoulos, S. Synthesis and characterization of hydroxyapatite crystals: A review study on the analytical methods. J. Biomed. Mater. Res. 2002, 62, 600-612. [CrossRef] [PubMed]

23. Sato, K.; Suetsugua, Y.; Tanaka, J.; Ina, S.; Monma, H. The surface structure of hydroxyapatite single crystal and the accumulation of arachidic acid. J. Colloid Interface Sci. 2000, 22, 423-427. [CrossRef] [PubMed]

24. Cheng, Z.H.; Yasukawa, A.; Kandori, K.; Ishikawa, T. FTIR study of adsorption of CO2 on nonstoichiometric calcium hydroxyapatite. Langmuir 1998, 14, 6681-6686. [CrossRef]

25. Ouyang, J.M.; Duan, L.; Tieke, B. Effects of carboxylic acids on the crystal growth of calcium oxalate nanoparticles in lecithin-water liposome systems. Langmuir 2003, 19, 8980-8985. [CrossRef]

26. Petit, I.; Belletti, G.D.; Debroise, T.; Llansola-Portoles, M.J.; Lucas, I.T.; Leroy, C.; Bonhomme, C.; Bonhomme-Coury, L.; Bazin, D.; Daudon, M.; et al. Vibrational signatures of calcium oxalate polyhydrates. Chem. Select. 2018, 3, 8801-8812. [CrossRef]

27. Fu, B.; Shen, Q.; Qian, W.; Zeng, Y.; Sun, X.; Hannig, M. Interfacial interaction of tartaric acid with hydroxyapatite and enamel. J. Mater. Sci. Mater. Med. 2005, 16, 827-831. [CrossRef] [PubMed]

28. Tarpara, U.; Vyas, P.; Joshi, M.J. Synthesis and characterization of calcium tartrate dihydrate nanoparticles. Inter. J. Nanosci. 2015, 14, 1550013. [CrossRef]

29. Lee, W.H.; Loo, C.Y.; Zavgorodniy, A.V.; Ghadiri, M.; Rohanizadeh, R. A novel approach to enhance protein adsorption and cell proliferation on hydroxyapatite: Citric acid treatment. RSC Adv. 2013, 3, 4040-4051. [CrossRef]

30. Shajan, X.S.; Mahadevan, C. On the growth of calcium tartrate tetrahydrate single crystals. Bull. Mater. Sci. 2004, 27, 327-331. [CrossRef]

Publisher's Note: MDPI stays neutral with regard to jurisdictional claims in published maps and institutional affiliations. 